\title{
Multi-agent model-based historical cropland spatial pattern reconstruction for 1661-1952, Shandong Province, China
}

Xiaomin Xiang, Juan Han, Wei Shan, Yeting Fan, Yinkang Zhou

\begin{abstract}
To advance the research of global land use/cover change (LUCC), biodiversity, global carbon cycle, and other aspects of the earth system, it is essential to reconstruct changes in historical cropland cover with long time series and high-resolution grid. Currently, it is a general approach which is based on the view of combining the overall control of cropland area, selecting
\end{abstract} grid of high land suitability, and 'top-down' decision-making behaviors to reconstruct the historical cropland. Considering various factors that influenced cropland distribution, including behavioral agent's selection by itself and the limitation of nature and human factors, a spatiotemporal dynamical reconstruction model of historical cropland based on the multi-agent systems has been developed from the perspective of 'bottom-up', which combine macroscopic and microscopic decision-making behaviors of agents to simulate the government and farmer autonomously implementing the selection behaviors of farming area. Taking Shandong Province as the study area, this model was used to imitate its cropland spatiotemporal pattern with $1 \mathrm{~km}$ grid-resolution from 1661 combining the contemporary pattern and reconstructed amount of historical cropland as a maximum potential scope and control variable of reconstruction model, respectively, furthermore, followed the accuracy valuation and comparative analysis. The reconstructed results show that: 1) It is properly suitable for Multi-Agent to simulate and reconstruct the spatial distribution of historical cropland; 2) Compared with historical map datasets (1930s) from the view of point to point, the correctly classified producer accuracy, user accuracy and overall accuracy of reconstructed result totally up to $59.09 \%, 80.62 \%$ and $62.31 \%$, 
respectively, and shows our reconstruction map achieved a better agreement with the historical maps; 3) From the view of grid-level or county-level, our reconstruction approach can effectively keep away from the grid with mountain-hilly and easily flooding probability, it showed a good similarity and higher consistency when compared with the research result based on archives and historical records in overall pattern and tendency of cultivation, and difference error decrease gradually, moreover, the cultivation ratios in county-level is more close to the historical situation.

Keywords: Multi-Agent; historical cropland; reconstructing spatial pattern; Shandong Province

\section{Introduction}

Land cover is the most obvious landscape indicator of terrestrial ecosystems. It is jointly affected by human land-use activities and natural processes (Li, 1996; Bai \& Zhao, 2001; IGBP, 2001). Meanwhile, land cover serves as the most direct signal for characterizing the influence of human activities on terrestrial ecosystems. Land cover provides a link between human economic activities and natural ecologies and can aid in the understanding of these interactions (Sterling, Ducharne, \& Polcher, 2013; Liu, Kuang \&Zhang, 2014). Historical land use and land cover variation is important when studying land use variation and global changes. Since the industrial revolution, under the stress of the global climate change and population explosion, land use patterns have frequently reflected human demands, such as cropland expansion, urban land use growth, and deforestation. These patterns changed the land coverage situation both temporally and spatially, and these trends also altered the sustainability of land use and land cover. Land use variation-related problems have gradually evolved from environmental problems to human 
habitat problems. These land-use problems even extend to issues of human survival (including climate change, eco-system process, biological geochemical cycling, and biodiversity). The problems are now investigated in various international interdisciplinary projects, and are becoming the focuses of academic circle (Feddema \& Oleson Bonan, 2005; Voldoire et al., 2007; Shi et al., 2007; Cao, Jin \& Zhou, 2013). In the mid-1990s, IGBP and IHDP which have been integrated into Future Earth initiated in 2014 jointly launched land-use and cover change (LUCC) project, in which it was emphasized that we must implement various approaches to reconstruct historical land use variation. This became the pilot study for historical land cover variation. Since then, historical land cover, especially reconstruction of high precision cropland spatial data, has received extensive attention (Ramankutty \& Foley, 1999; Klein Goldewijk, 2001; Hurtt et al., 2006; Pongratz et al., 2008; Kaplan, Krumhardt \&Zimmermann, 2009; Zhu, Cui \& Miao, 2012; Long et al., 2014; Yang et al., 2015a/b; Wei et al., 2015).

LUCC is an essential variable in climate change simulations at large temporal scales, diagnosis of climatic formation mechanism, identification of sensitivity of climate system to natural and human drivers, and prediction of future climate changes. LUCC also represents key fundamental data to analyze, simulate, and predict global (or local) eco-environmental changes. Meanwhile, it is also the cornerstone to achieve scientific targets such as the establishment (reconstruction) of long term (most recent 300 years or more), continuous (time continuity), and high resolution (1-10 km grid) land cover data (Klein Goldewijk \& Ramankutty, 2004; Ye \& Fu, 2004; Foley et al., 2005). The majority of recent studies on the reconstruction of spatiotemporal continuous historical land cover have been at medium and large scales. SAGE, HYDE, and Pongratz's dataset are examples of such data sets that were created on a global scale (Klein Goldewijk \& Battjes, 1997; Ramankutty \& Foley, 1999; Pongratz et al., 2008). At 
national scales, the cropland data set developed by Tian et al. (2014), Feng et al. (2014), and Li et al. (2015); the forest land data set of He et al. (2015); and the multi-land type data set of Liu \& Tian (2010) and Mazier et al. (2015) are prominent instances. Most of these data sets summarize natural and human factors such as regional natural resource condition, population growth, and contemporary land use structure. Taking "cultivation suitability" and "reclamation availability" as core indicators, the transition probability and change rate were set for certain types of land use over specific time periods, thereby achieving "top-down" spatial distribution of corresponding land type. The effectiveness of the reconstruction results depends upon the richness and veracity of historical data (i.e., accuracy of number of land use types and level of detail for basic elements in data acquisition) as well as the rationality of spatial boundary control (level of detail in regional division for reconstruction and availability of historical assessment indicators). For example, contemporary population density was taken as the base map of land use pattern distribution in the global data product HYDE versions 1.1(Klein Goldewijk \& Battjes, 1997) and versions 2.0 (Klein Goldewijk, 2001), and land type areas were distributed based on historical population data. The SAGE data set (Ramankutty \& Foley, 1999) collected historical land statistics at a national scale. Using land use pattern interpreted from contemporary remote sensing images as a base map, the ratio of historical statistics and area data from remote sensing interpretation was used to assign historical land type onto the base map. However, several studies have indicated that, due to coarse cropland quantity estimation and spatial distribution methods, the above data sets are only suitable for global scales and should not be used for regional studies (Li et al., 2010; He et al., 2010).

The abundant literature on Chinese history significantly benefits historical LUCC reconstruction. Based on historical materials (land tax, local chronicles, historical chronicles, 
place name chronicles, travel notes, personal notes, topographic maps, cadastral maps, and landscape maps), data have been collected, recovered, screened, modified, and spatialized according to temporal and spatial scale. This has provided beneficial data for qualitative and semi-quantitative analysis of historical LUCC. However, due to limited richness and identifiability of historical data in different spatiotemporal scales, the majority of recent studies focused on areas with complete local administration units and geographic forms (Lin, Zheng \& He, 2009; He, Li \& Zhang, 2011; Xie et al., 2013; Li, He \& Zhang, 2014; Zhang et al., 2014; Luo et al., 2014; Lin et al., 2015). This has resulted in a situation where the precision of the "top-down" spatial distribution method encounters a bottleneck when approaching a certain level (village or county) of administration unit. To improve reconstruction efficiency and to properly explain the change process, it has become common to utilize the "bottom-up" spatial evolution of historical land use pattern in conjunction with cellular automata that characterize human land use activities. Given verification of objective data in certain time section (point-to-point verification, pattern verification, tendency verification, etc.), the explanatory power of reconstruction results could be elevated. Because of flexible transition rules, dynamic spatiotemporal variation, and "top-down" spatial evolution, cellular automaton (CA) models have been successfully applied in historic LUCC land reconstruction (Bai, Zhang \& Zhang, 2007; Long et al., 2014; Yang et al., 2015b). However, the method is unable to describe the interaction and negotiation mechanism between behavioral subjects, and therefore cannot reflect the causes or mechanism of land use pattern changes. In addition, only constraint factors in adjacent regions were considered in pervious CA models and the cells cannot move. To overcome the limitations of the above method, Multi-Agent Systems (MAS) were introduced into historical cropland spatial pattern reconstruction to further consider the complex behavior and interaction of behavioral subjects in 
the regional selection process. The essence of historical cropland gridding reconstruction is to simulate the spatial regional selection and decision-making behavior of behavioral subjects in a historical period after accounting for tradeoffs between various geographic environmental elements, and thereby perform site selection of potential cultivation area. MAS integrate complex adaptive system theory, artificial life and distributed artificial intelligence technology. The "bottom-up" approach, a powerful and complex calculation function, as well as spatiotemporal dynamic characteristics make MAS well suited to simulate regional site selection in a complex spatial system (Zhang et al., 2008).

On the basis of MAS theory, a spatiotemporal dynamic historical cropland reconstruction model was established. This model was able to describe the interactions between agents that influence cropland site selection. Due to the availability of detailed historical data, Shandong province was taken as an example to reconstruct the cropland spatial pattern of a typical historical period using the reconstructed model. This method will hopefully provide a new perspective for future studies on historical cropland spatial pattern reconstruction.

\section{Methodology}

\subsection{Modelling framework}

Current cropland spatial pattern is the result of human impact on the terrestrial system, and the current pattern indirectly includes historical cropland pattern information (Klein Goldewijk, 2001; Zhu, Cui \& Miao, 2012). From the beginning of Qing dynasty to 1980, the total cropland area of traditional region in China increased with fluctuations (Yang et al. 2015b). The cropland area peaked between 1978 and 1980 and then decreased dramatically. Therefore, the cropland area in 1980 was taken as the outer boundary of historical cropland distribution (Zhou, 2001;

Zhang, Liu \& Zhang, 2003; Feng, Liu \& Yang, 2005). For cultivation area site selection, the 
agent is assumed to be rational with utility seeking behavior (i.e., pursues higher benefits and avoids hazards). While determining whether or not to cultivate a certain land at a certain moment, the behavioral subject may have certain willingness for both cultivation or abandonment based on the considerations of investment, production, and agricultural cultivation risks. When the willingness for cultivation exceeds the willingness for abandonment, the land will be cultivated as cropland by the behavioral subject.

Cellular automata and multi-agents are the two components of the proposed model. Cells are used to characterize various immovable, discrete, and distributed geographic elements in the study area, such as elevation, slope, river system, precipitation, soil fertility, town, and contemporary land use pattern. In contrast, multi-agents are used to simulate moveable behavioral subjects in the geographic environment. Considering data availability and model complexity, two types of agents were selected in this study to characterize the decision-making of different behavioral subjects, i.e., a macro-agent (government agent) and micro-agents (farmer agent). Other agents were not considered. The macro-agent represents governmental use control or encouragement for land development within the territory scope, such as the special purposes of hunting parks, summer resorts, ore extraction, and sea salt solarization. The micro-agent acquires knowledge on cropland cultivation (for example, the locations of fertile soil, flat terrain, or severe flood risk) from experience and observation, and the agent then conducts land cultivation activities. Multi-agents and the geographic environment are not independent, as the geographic elements directly affect spatial decision-making behavior of multi-agents, and vice versa. The basic framework of the model is shown in Fig. 1. The model was constructed based on the following assumptions: (1) historical cropland spatial pattern did not exceed the outer boundary of contemporary cropland. In other words, the case in which historical cropland was 
non-cropland at present does not exist. (2) Water bodies could not be transformed into cropland. (3) Micro-agents performed cultivation activities along the positive time axis within the potential cropland distribution range.

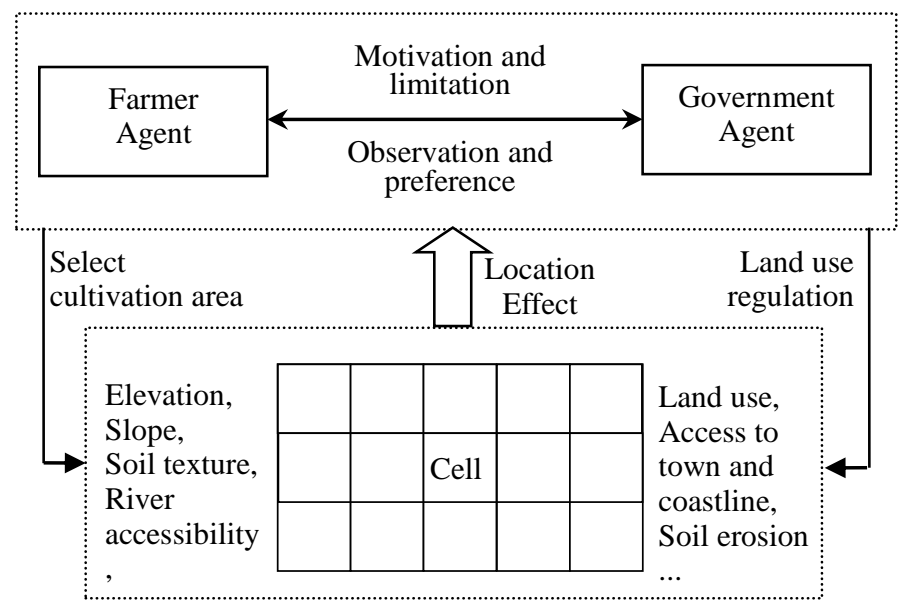

Fig.1 the framework of reconstructing historical cropland based on MAS and CA

\subsection{Multi-agent model-based historical cropland spatial pattern reconstruction and}

\section{decision-making rules}

\subsubsection{Decision-making rule of governmental agent}

Government is a special type of agent because it does not have spatial properties; however, it can restrict or encourage regional land development through setting use controls or expressing support for cultivation. Since the beginning of the Qing dynasty, the government has restricted agricultural cultivation in regions with special significance, such as the three provinces of northeast China and the imperial Chengde Mountain Resort. Meanwhile, years of war in China resulted in large amounts of abandoned and barren cropland in traditional agricultural areas. In order to restore agricultural production, the government encouraged reclamation and broadened cultivation through providing land to homeless people, encouraging cultivation, and protecting farmer's benefits. The government established offices to manage the process. Based on Liu et 
al.(2010) and Zhang et al.(2008) 's research results, the land cultivation probability of governmental agent at moment $t\left(P_{-} a l_{i}^{t}\right)$ can be expressed as Formula (1), which is characterized by cultivation restriction $\left(P_{-} r e_{i}{ }^{\dagger}\right)$, encouragement $\left(P_{-} e n_{i}{ }^{\dagger}\right)$, and random interference of cell unit $i$.

$$
P_{-} a l_{i}^{t}=\alpha_{1} \times P_{-} r e_{i}^{t}+\alpha_{2} \times P_{-} e n_{i}^{t}+\varepsilon
$$

Where: $P \_a l_{i}^{t}$ is the government agent cultivation probability of land in cell unit $i$ at moment $t$. Larger values indicate that less government use control is applied to the characterized land unit which results in a higher cropland development potential. $P_{-} r e_{i}^{t}$ and $P_{-} e n_{i}^{t}$ are cultivation restriction and encouragement of cell unit $i$ at moment $t ; \alpha_{1}$ and $\alpha_{2}$ are spatial weights of restriction and encouragement, respectively; and $\varepsilon$ is random interference term.

\subsubsection{Decision-making rule of farmer agent}

Cultivation area site selection is the core part of the model, during which farmer agents exhibit behaviors of observation, comparison, and land use preference (Zhang et al., 2015). Considering the relations of investment, production, and cultivation risks, farmer agents observe cell unit $i$ at moment $t$. The agents then compare cultivation feasibility and potential risks in production, namely the willingness for cultivation or abandonment for cell unit $i$ at the same moment. If the cultivation feasibility of cell unit $i$ at moment $t$ exceeds the production risks, the farmer agent will decide to cultivate cell unit $i$.

\section{(1) Willingness of cultivation}

Farmer agents are the primary behavioral subject of cropland cultivation. These agents select land to perform agricultural cultivation based on profit maximization. Farmer agents carry out discrimination and then implement corresponding behavior based on years of cultivation experience, communication, and local eco-environmental conditions. If the land exhibits fertile soil, accessible drainage and irrigation, and a sufficient water source in the vision field, priority 
of cultivation would be obtained from the farmer agent. Based on Long et al. (2014) and Yang et al. (2015b) 's literatures, the decision of farmer agents to cultivating land $i$ at moment $t$ depends on the cultivation availability of the cell $\left(S_{i}^{t}\right)$; the assessment factors of land availability that characterize terrain background values, such as terrain elevation, slope, and relief amplitude; soil (including soil texture, total N, P, K, and organic matter); $\mathrm{pH}$ value; and adjacent water system distance reflecting accessibility of drainage and irrigation. Logistic regression model is then adopted to calculate the contribution probability of each factor $\left(P_{-}\right.$rec $\left._{i}{ }^{\dagger}\right)$ (Formula 2 and 3):

$$
\begin{gathered}
S_{i}^{t}=\beta_{0}+\beta_{1} \times L_{-} \text {bottom }_{i}^{t}+\beta_{2} \times Q_{-} \text {soil }_{i}^{t}+\beta_{3} \times A_{-} \text {river }_{i}^{t} \\
P_{-} \text {rec }_{i}^{t}=\frac{1}{1+e^{-s_{i}^{t}}}
\end{gathered}
$$

Where: $S_{i}^{t}$ is the land cultivation availability of cell unit $i$ at moment $t$. L_bottom ${ }_{i}{ }^{\text {, }}, Q_{\_}$soil $_{i}{ }^{t}$, and $A \_$river $_{i}^{t}$ characterize terrain background values, soil texture, and accessibility of irrigation and drainage of cell unit $i$ at moment $t . \beta_{0}$ and $\beta_{1-} \beta_{3}$ are the preference coefficients of farmer agents for each of the influential factors, respectively. The values were obtained using logistic regression analysis. $P_{-} \operatorname{rec}_{i}^{t}$ is land availability contribution probability of land unit $i$ at moment $t$.

\section{(2) Willingness for abandonment}

Although land cultivation feasibility of cell unit $i$ at moment $t$ might be high, due to interference from various natural, social, and economic factors, cell unit $i$ may not be suitable for cultivation. During the Qing dynasty, there were various wars, natural flood disasters, frequent epidemics, and environmental deterioration that resulted in massive areas of fertile soil becoming unsuitable for cultivation. Based upon considerations of avoiding wars and disasters as well as reducing agricultural cultivation risks, farmer agents would not be willing to cultivate certain areas. In view of data availability, the abandonment behavior of farmer agents was considered as a result of flooding disaster, soil erosion, and land use restriction by government agent since the 
Qing dynasty. The decision-making rule of farmer agents with respect to willingness to abandon land in their vision field is presented in Formula (4):

$$
P j_{i}^{t}=\rho_{1} \times S k_{i}^{t}+\rho_{2} \times \text { Erosion }_{i}^{t}+\rho_{3} \times P_{-} r e_{i}^{t}
$$

Where: $P j_{i}^{t}$ is the abandonment probability of a farmer agent for cell unit $i$ at moment $t$. $S k_{i}^{t}$ is the risk of flooding in cell unit $i$ at moment $t$ Erosion $_{i}{ }^{t}$ is the soil erosion coefficient of cell unit $i$ at moment $t . P_{-} r e_{i}{ }_{i}$ is the level of cultivation control in cell unit $i$ at moment $t$. As in Formula (1), $\rho_{1}, \rho_{2}$, and $\rho_{3}$ are the preference coefficients of the above three variables.

\section{(3) Probability for cultivation}

Whether a farmer agent cultivates cell unit $i$ at moment $t$ depends on the location effect of cell unit $i$. The site selection and decision-making method referenced the studies of Liu et al. (2010) as well as Brown \& Moore (1970). The probability of a farmer agent cultivating a cell should be equal to or larger than the probability of any other candidate land in the vision field. According to the validation of McFadden (1974), for farmer agent, the location effect probability of cell unit $i$ at moment $t$ can be expressed as in Formulas (5-6):

$$
\begin{gathered}
U_{i}^{t}=P_{-} r e c_{i}^{t}-P j_{i}^{t}+\xi \\
P_{-} c u_{i}^{t}=\exp \left(U_{i}^{t}\right) / \sum \exp \left(U_{i}^{t}\right)
\end{gathered}
$$

Where: $U_{i}{ }^{t}$ is the location effect of cell unit $i$ at moment $t$ for a farmer agent. $P \_r e c_{i}{ }^{t}$ and $P j_{i}{ }^{t}$ are the contribution probability of land suitability and abandonment probability of cell unit $i$ at moment $t$, as in Formulas 3 and $4 . \xi$ is a random interference term. $P_{-} c u_{i}{ }^{t}$ is the location effect probability for a farmer agent at cell unit $i$ at moment $t$.

\subsubsection{Negotiation rule between farmer agents}

Considering neighbor cooperation and production tool complementary in agricultural societies, appropriately concentrated cultivation could benefit agricultural production and 
prevent production risks. Therefore, farmer agents prefer to cultivate concentrated lands. When selecting cultivation area, farmer agents consider neighbor cropland density and the number of applications put in by other farmer agents for the land unit. The land with higher neighbor cropland density and cultivation willingness will have a higher chance of being selected as cropland. Based on the studies of Zhang et al. (2015) and Yang et al. (2015a), the negotiation rules are Formulas 7:

$$
P k_{i}^{t}=P k_{i}^{0}+\Delta p_{1} \times \text { Dencropland }{ }_{i}^{t}+\Delta p_{2} \times g
$$

Where: $P k_{i}{ }^{t}$ is the final probability of cell unit $i$ accepted by a farmer agent as cropland at moment $t . P k_{i}{ }^{0}$ is the initial probability of cell unit $i$ accepted by a farmer agent as cropland at moment $t$. Dencropland ${ }_{i}^{t}$ is the quotient of cropland cell numbers and total adjacent cell numbers in the Moore neighborhood of cell $i$ at moment $t$, as seen in Formula (8). $\Delta p_{1}$ is the increased acceptance probability in the Moore neighborhood of cell unit $i$ with one additional cropland. $g$ is the number of farmer agents considering cell unit $i$ for cropland, and $\Delta p_{2}$ is the increased acceptance probability with one more petition.

$$
\text { Dencropland }_{i}^{t}=\left(\sum_{i=1}^{8} \text { cell }_{i}^{t} \in \text { cropland }\right) / 8
$$

\subsubsection{Establishment of synthetic decision-making rule}

The historical cropland spatial pattern is the result of synthetic decision-making from macro-agents and micro-agents. Based on the above decision-making rule and the results of Zhang et al. (2015), the synthetic decision-making rule of historical cropland spatial pattern could be obtained by Formulas 9:

$$
P d_{i}^{t}=\exp \left[\alpha\left(\frac{R_{i}^{t}}{R_{g \text { max }}^{t}}-1\right)\right]
$$

Where: $P d_{i}{ }_{i}$ is the final probability of cell unit $i$ being cultivated as cropland at moment $t$, with 
a higher value indicating higher probability of cell unit $i$ being used as cropland. $R_{\text {gmax }}^{t}$ is the maximum value of the potential cultivation cell set composed of all cell units in the operation. $\alpha$ is a discrete parameter and ranges $1-10 . R_{i}^{t}$ represents the potential cultivation probability of cell $i$ due to the joint action of both macro- and micro-agents. The calculation model is shown below in Formula (10):

$$
R_{i}^{t}=K \times\left(\tau_{1} \times P_{-} a l_{i}^{t}+\tau_{2} \times P_{-} c u_{i}^{t}+\tau_{3} \times P k_{i}^{t}\right)
$$

In which: Definitions of $P_{-} a l_{i}{ }^{t}, P_{-} c u_{i}^{t}$, and $P k_{i}{ }^{t}$ are the same as above. $\tau_{1}, \tau_{2}$, and $\tau_{3}$ are the weight of each multi-agent in the model. $K$ is the cultivation restriction factor, which is based on the rule shown in Formula (11):

$$
K= \begin{cases}0 & \text { If } \text { cell }_{i} \text { is waterbody } \\ 1 & \text { Else }\end{cases}
$$

\section{Case Study}

\subsection{Study area and data sources}

\subsubsection{Study area}

Shandong Province is located along the eastern coast of China near the lower reaches of the Yellow River and the northern central region of the Beijing-Hangzhou Grand Canal. During the Ming and Qing dynasties, Shandong encompassed an area that included most parts of modern Shandong Province (except the counties of Dongming, Ningjin and Qingyun); the counties of Fanxian and Taiqian in Henan Province; as well as Guantao County, Qiuxian County, the southwest of Gucheng County, and the southeast of Haixing County in Hebei Province. Considering the need for connecting historical data with modern data and research results, Shandong Province under modern administrative division is selected as the study area. With a land area of $1.57 \times 10^{5} \mathrm{~km}^{2}$, plain regions (including basin and tableland) cover $64 \%$ of the area 
and $35 \%$ is covered by mountain land and hills. This region is characterized by a temperate monsoon climate. With adequate sunshine and moderate rainfall, it has traditionally been the major grain production base in China. This paper proposes a reconstruction period from 1661 to 1952. The starting point of backward modeling was the status of land use in the study area in 1980 as obtained by remote sensing interpretation (http://www.geodata.cn /data/dataresource.html?publisherGuid=126744287495931\&categoryld=22 $)$. The cropland area in 1980 was determined to be $1.10 \times 10^{5} \mathrm{~km}^{2}$, and it occupied $69.66 \%$ of the total study area. The cropland was well distributed, except in the hilly areas in the center and northeast where the amount of cropland is low. Since cultivation areas on isolated islands are difficult to identify and have low probability of existence, they are not initially considered (Fig. 2a).

During the Qing dynasty, land development in Shandong Province exhibited different patterns. In addition to agricultural cultivation, coal and sea salt exploitation were also conducted to some degree. During the Shunzhi dynasty, coal mining was conducted just in one county of Shandong province, and this number increased to 8 during the Kangxi dynasty, 21 during the Qianlong dynasty, and 17 states and counties during the Xuantong dynasty (Pei, 2014). In the early period of the Qing dynasty, there were 19 salt fields distributed along Bohai Bay which were kept operational during the Ming dynasty. After adjustment and merging, this number decreased to 8 in 1833 . Then in 1855 , the coastal outflow of the Yellow river was shifted to the Daqing River, resulting in floods at the Yongfu salt field. Therefore, the number of salt fields changed to 7 (Ji, 2014). In addition, Yellow River dikes in Shangqiu, Yangwu and Lanyang of Henan always broke, and one branch of floods flew into Nanyang Lake in west Shandong along Baihua River, Lai River and Anglin River, while the other branch merged into Daqing River before entering the sea along Zhaowang River, Wei River, and Zhangqiu Canal River. The floods caused frequent 
disasters in West and North Shandong plain and places along Daqing River like Dongping, Pingyin, Dong'e, Changqing (Li, 1993). Based on places name database of Shandong in Qing dynasty, the geographic elements were spatialized (Fig. 2b).

(a)
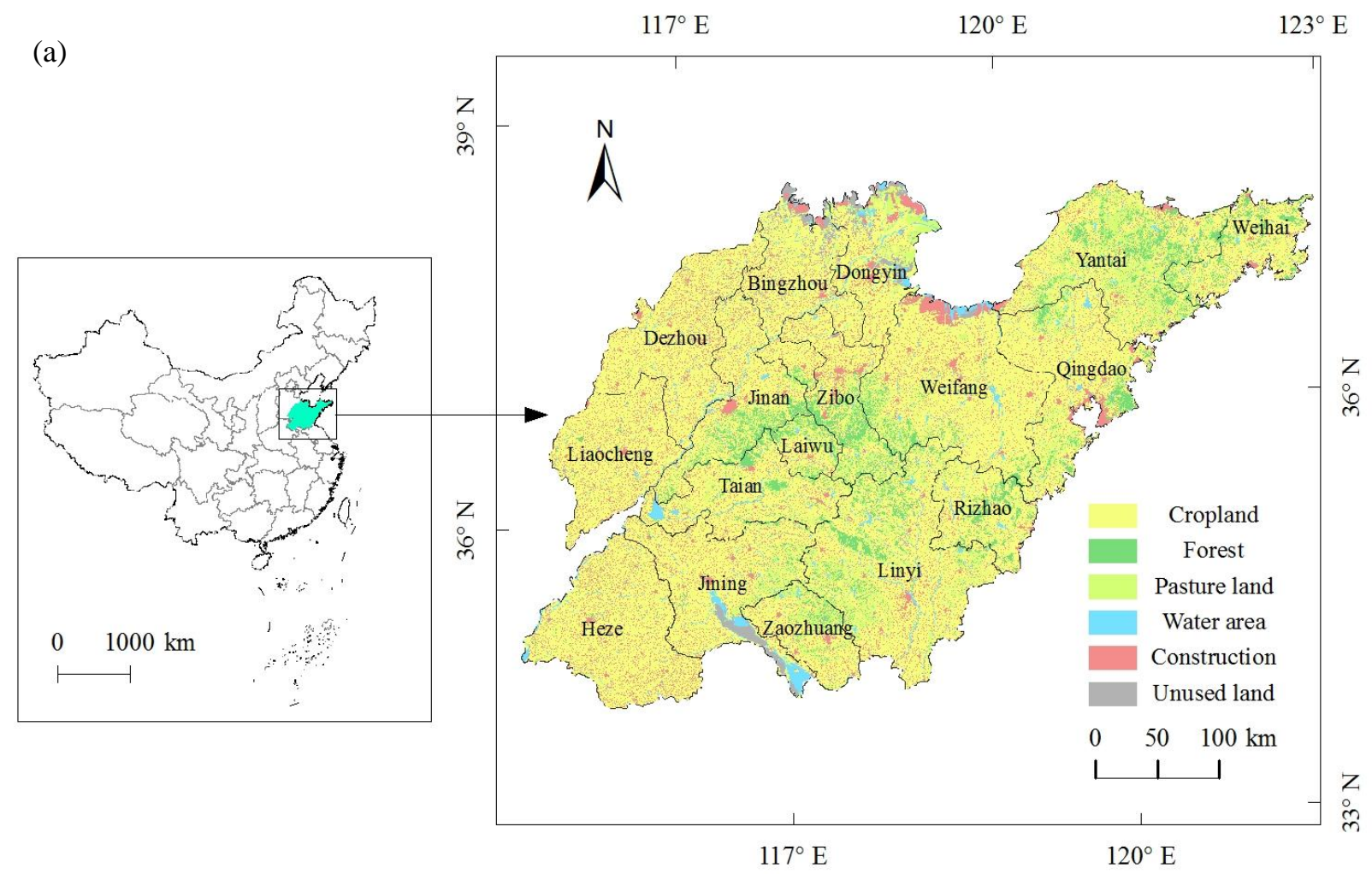

(b) 


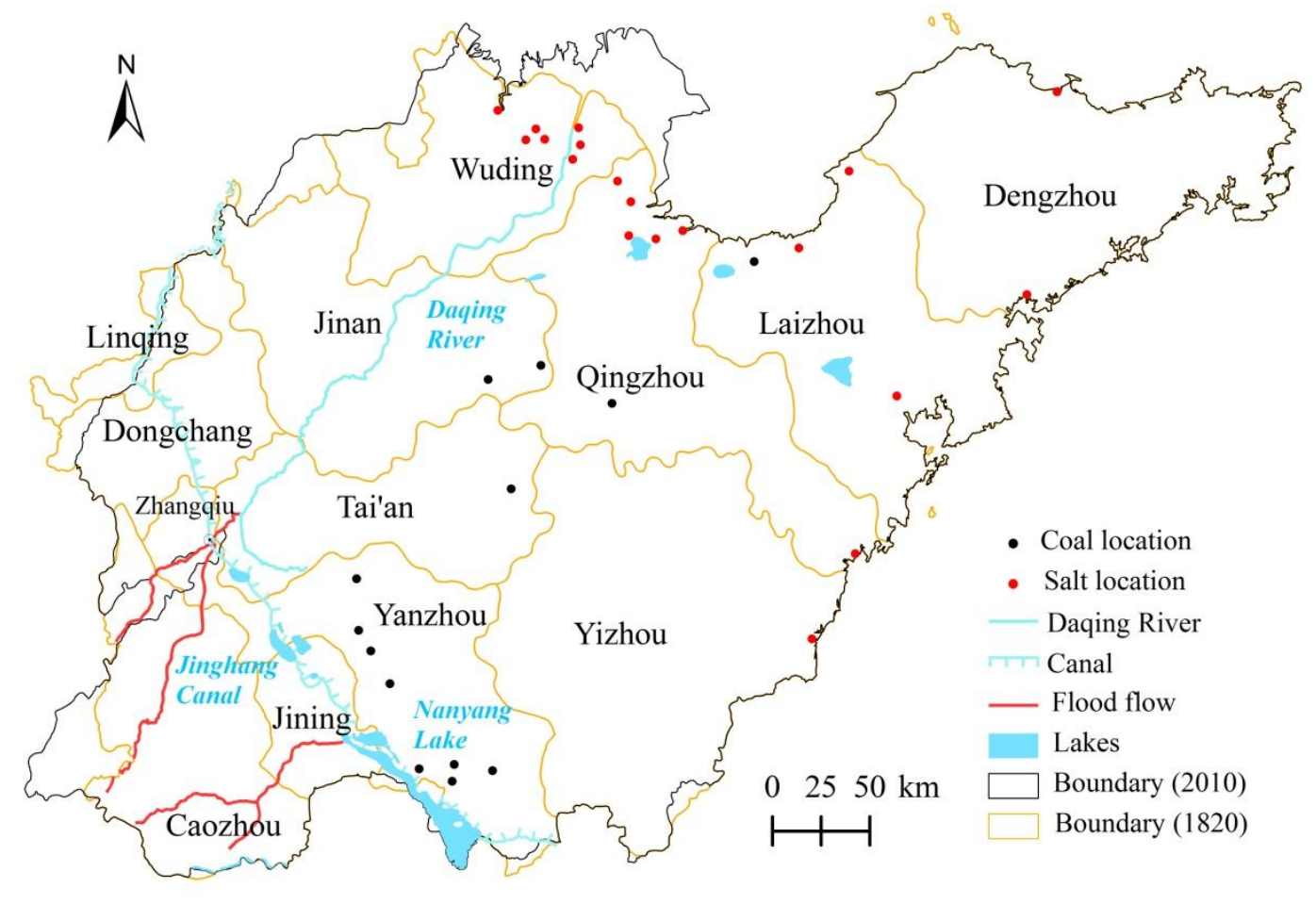

Fig. 2 The current land use in 1980 (a) and geographical features in Qing Dynasty (b) of Shandong Province

\subsubsection{Data resources and processing}

(1) Amount of historical cropland: cropland from 1661 to 1952 was based on the research of Cao et al. (2013) combined with the 1933 data from 'China's statistical analysis of land issues' (Statistical Bureau of the National Government of China, 1936).

(2) Historical town and village location: location data of Shandong Province in 1820 and 1911 are adopted from the Chinese Historical Geographic Information System (CHGIS) which was obtained from the Harvard University CHGIS database (http://gis.harvard.edu ).

(3) Topographic data: the DEM was provided by Geological Survey's Center for Earth Resources Observation and Science U.S. (https://lta.cr.usgs.gov/GTOPO30 ).

(4) River network and lake data: basic geographic data of the river network and lakes of China were obtained from the National Geomatics Center of China (1:4 000 000). They are divided into grades 1 to 5 according to river lever (http://www.geodata.cn/data/publisher.html ). 
(5) Soil erosion data: the results of the second national soil erosion research by remote sensing are adopted. $1 \mathrm{~km} \times 1 \mathrm{~km}$ spatial grids are generated by the maximum area method (http://www.geodata.cn/data/datadetails.html?dataguid=243299271611403\&docId=901 ).

(6) Physicochemical data of soil: the data of the China Soil Scientific Database of the Institute of Soil Science, Chinese Academy of Sciences are adopted. The analysis indices include $\mathrm{pH}$, organic matter, total $\mathrm{N}$, total $\mathrm{P}$, and total $\mathrm{K}$ (surface soil 0-20 cm; spatial resolution $2 \mathrm{~km} \times 2 \mathrm{~km}$; http://www.geodata.cn/data/dataresource.html ).

(7) Salt field and coal mine data: The data of salt fields in Shandong between 1677 and 1894 came from the modified results of $\mathbf{J i}$ (2014), and the data of coal mines were derived from a modification of Pei (2014)'s results.

\subsection{Process modeling and implementation}

Assuming that every cropland cell unit contains only one farmer agent, then the number of farmer agent at different stages can be determined based on historical cropland quantity of every typical year (modified data from Cao et al. 2013) It is worth noting that the farmer agent here only reflects a proportion relationship, which is characterized by occupied land cell number. The specific process of the model is as follows:

1) The number of agents at different time cross sections was determined based on cropland modification quantity. Then, a Monte Carlo method was used to randomly generate the required farmer agents in the contemporary cropland distribution range. In order to increase the model calculation speed, we followed the method of Long et al.(2014), i.e., the number of farmer agents at the $h$ iteration was set to be equal to the total agent number divided by the pre-set iteration number.

2) A cellular automata model is used to calculate land cultivation probability, cultivation 
suitability, and abandonment probability of cell unit $i$ at moment $t$ under governmental control.

3) Formulas (6), (7), and (8) are used to calculate the location effect value of farmer agent and cultivation probability of cell unit i given mutual negotiation of farmer agent.

4) The synthesis of multi-agents decisions, based on Formulas (9) and (10), determines whether the cell unit with maximal cultivation probability in the vision field of a farmer agent is cultivated as cropland. If so, then cultivation location selection of the next farmer agent will begin. If cropland cell selection is not finished by a certain farmer agent, the model returns to the multi-agent synthetic decision-making stage and continues until all multi-agents finish site selection.

\subsection{Identification and quantification of parameters}

Considering the typicality of cropland elements characteristics, availability of model data in calculation, scale cohesion with relative studies (climate simulation and carbon cycle), and convenience of stacking with existing data, the spatial resolution in this study was set at $1 \mathrm{~km} \times 1$ $\mathrm{km}$, and cultivation adaptability ranged from 1 (most suitable) to 0 (least suitable).

1) Land cultivation restriction value

Shandong is one of the major agricultural provinces in China. Except for coal mining areas and government-run salt fields, the government agent encourages land development in the jurisdiction. Cultivation restriction value of government agent $\left(P_{-} r e_{i}^{t}\right)$ was characterized by the distances between cell unit $i$ and coal mines, salt fields, and coast line at moment $t$, as seen in Formula (12). It was normalized based on the theory of exponential decay with inverse distance for spatial influences.

$$
P_{-} r e_{i}^{t}=\alpha_{1} \times d t o c_{i}^{t}+\alpha_{2} \times d t o s_{i}^{t}+\alpha_{3} \times d t o l_{i}^{t}
$$

Where, $\operatorname{dtoc}_{i}{ }_{i}, d \operatorname{tos}_{i}{ }^{t}$, and $d$ tol $_{i}^{t}$ are the distances between cell unit $i$ and coal mines, salt fields, 
and coast line at moment $t$, respectively. $\alpha_{1}, \alpha_{2}$, and $\alpha_{3}$ are the corresponding spatial weights, and they are all set equal to $1 / 3$.

\section{2) Land cultivation encouragement value}

The regulation department is the main organization that controls land cultivation and taxation in the jurisdiction. Its spatiotemporal pattern change can effectively reflect the encouraging attitude of government for land cultivation and the local land cultivation process (Fang et al., 2005). Cultivation encouragement value $\left(P_{-} e n_{i}{ }^{\dagger}\right)$ of the government agent is characterized by the distance between cell unit $i$ and regulation department (in town) at moment $t$, as shown in Formula (13).

$$
P_{-} e n_{i}^{t}=\exp \left(-d_{i} / \max \left(d_{i}\right)\right)
$$

In which: $d_{i}$ is the distance between cell unit and the nearest regulation department, and $\max \left(d_{i}\right)$ is the maximum distance between cell unit $i$ and the nearest regulation department.

3) Contribution probability of Land cultivation adaptability is based on the land cultivation adaptability calculation method presented in section 2.2. Terrain background values, such as terrain elevation, slope, relief amplitude, soil quality (including texture, total N, P, K, and organic matter), $\mathrm{pH}$ value, and adjacent water system distance reflecting accessibility of drainage and irrigation were considered as the main factors of land adaptability assessment. Cropland pattern status in 1980 was selected as the dependent variable. Then, the regression values of all factors were obtained based on a logistic regression model (Table 1). The quantification method of the factors can be found in the study of Yang et al. (2015a).

Table 1 Prediction accuracy by logistic

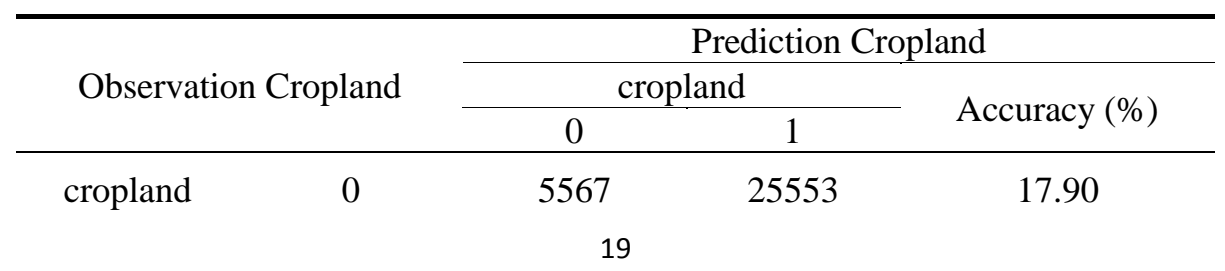




\begin{tabular}{rccc}
1 & 3419 & 118353 & 97.20 \\
Total accuracy (\%) & 61.95 & 82.24 & 81.10 \\
\hline
\end{tabular}

4) Land abandonment probability

According to Formula (4), the land flood risk coefficient $S k_{i}^{t}$ can be calculated via exponential decay based on the distance between cell unit $i$ and a major broken dike at moment $t$. According to Yang et al. (2015a), soil erosion is divided into water erosion and wind erosion. Based on expert opinion in Table 2, soil erosion coefficient $\left(\right.$ Erosion $\left._{i}{ }^{\dagger}\right)$ is assigned to different types and levels of land.

Table 2 Land suitability value under different types and intensities of soil erosion

\begin{tabular}{ccccccc}
\hline \multirow{2}{*}{ Types } & \multicolumn{7}{c}{ Intensity level } \\
\cline { 2 - 7 } & Micro & $\begin{array}{c}\text { Mid } \\
\text { degree }\end{array}$ & $\begin{array}{c}\text { Moderate } \\
\text { degree }\end{array}$ & $\begin{array}{c}\text { Strength } \\
\text { degree }\end{array}$ & $\begin{array}{c}\text { Severe } \\
\text { degree }\end{array}$ & $\begin{array}{c}\text { Extremely severe } \\
\text { degree }\end{array}$ \\
\hline $\begin{array}{c}\text { Eroded by } \\
\text { water }\end{array}$ & 0.95 & 0.80 & 0.75 & 0.50 & 0.30 & 0.10 \\
Eroded by wind & 0.95 & 0.75 & 0.70 & 0.40 & 0.20 & 0.10 \\
\hline
\end{tabular}

Note: Engineering erosion only presented in $1.45 \mathrm{~km}^{2}$ in Shandong Province, thus, conclude it into its adjoining erosion to simplify the classification

Summarizing the above-mentioned quantification and parameter setup, the spatial data pattern can be obtained, as shown in Table 3. It was assumed that land cultivation adaptability values did not change significantly in the intervening 300 years, while social environmental variables used dynamic data.

Table 3 Patterns and weights of spatial factors influencing cropland distribution

\begin{tabular}{ll||lr}
\hline & & & \multicolumn{2}{c}{ Spatial pattern } \\
\cline { 3 - 4 } Factors & Spatial pattern $\quad$ Parameters & Factors & $\begin{array}{c}\text { The middle and latter } \\
\text { period in Qing Dynasty }\end{array}$ \\
\cline { 3 - 4 } & & Early Qing Dynasty &
\end{tabular}




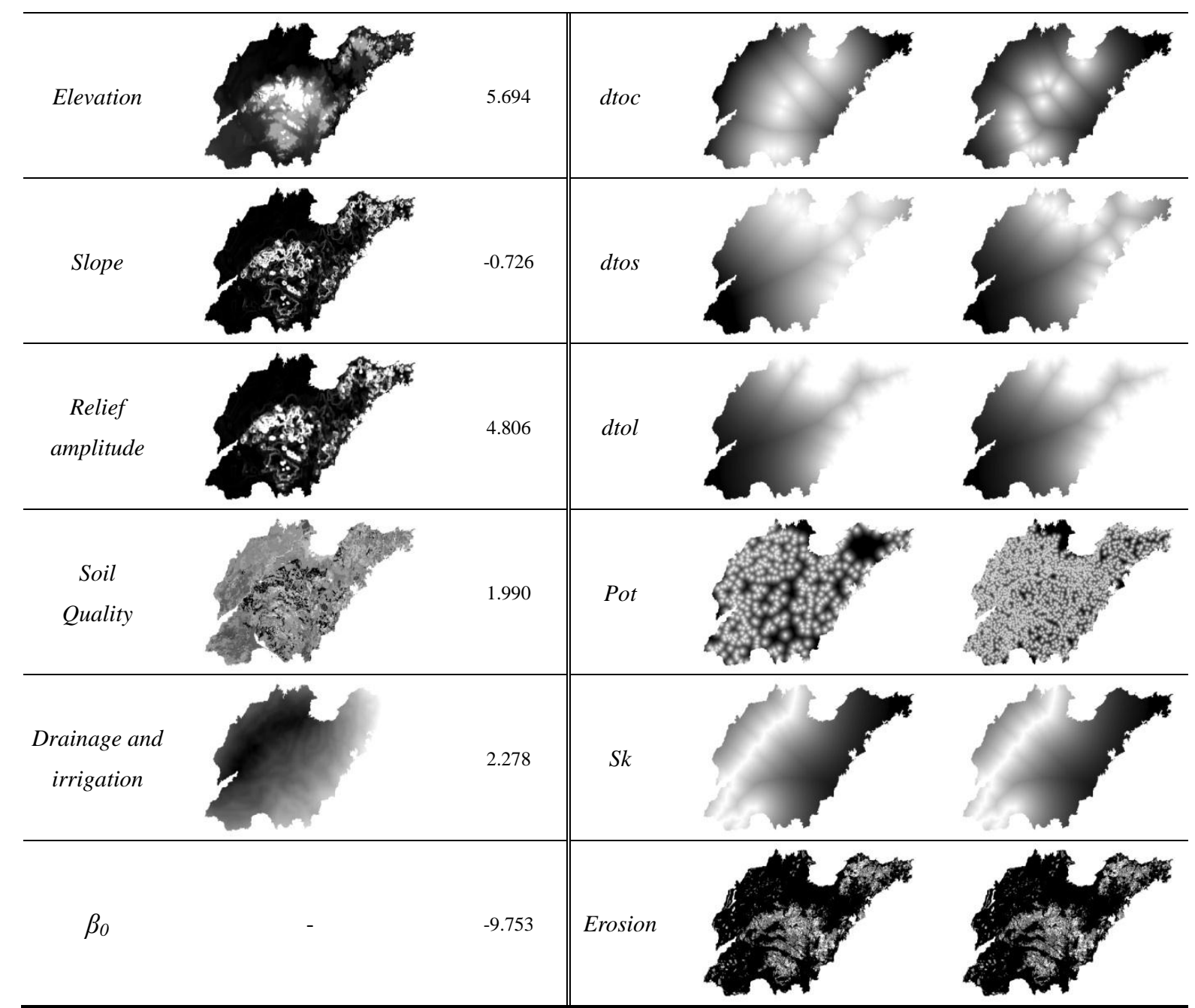

Note: In the left spatial elements graph, a brighter color represents a higher value, while the opposite is the case in the right graph.

5) Historical cropland and multi-agent quantity in typical years can be found in the study of Cao et al. (2013). Cropland quantities for 6 period cross sections between 1661 and 1952 were selected as the control variable of multi-agent quantity (Table 4).

Table 4 the area of reconstructing cropland in different periods

\begin{tabular}{ccccccc}
\hline Years & 1661 & 1724 & 1820 & 1887 & 1933 & 1952 \\
\hline $\begin{array}{c}\text { Historical cropland } \\
\text { quantity } / \mathrm{km}^{2}\end{array}$ & 47327 & 67079 & 85446 & 83268 & 97717 & 92440 \\
\hline
\end{tabular}

\subsection{Results and analyses}

The model was programmed using Java in the Repast Simphony 2.0 platform. The Repast 
platform provides a multi-agent simulation environment and a class library, which not only reduces model realization difficulty but also displays step-by-step results in real time. The data needed for the model was generated in ArcGIS 9.3. Interaction between ArcGIS and Repast platform was enabled using .txt files.

\subsubsection{Validation of Model}

In order to verify parameter settings in the model and to evaluate the reliability of the reconstruction results, the reconstruction results were compared point-by-point with historical map data. Referencing the research results of Fuchs et al. (2015), producer precision, user precision, and overall precision were adopted as indicators of performance. The associated Formula is as follows:

$$
\begin{gathered}
p_{-} a=c c n m / a c n h m \times 100 \% \\
u_{-} a=c c n m / a c n m \times 100 \% \\
o_{-} a=c m / t m \times 100 \%
\end{gathered}
$$

Where, $p \_a, u \_a$, and $o \_a$ represent producer precision, user precision, and overall precision, respectively. ccnm is the number of sample points that are accurately simulated as cropland. acnhm is the number of sample points that are cropland in the historical map. acnm is the number of sample points simulated as cropland. $\mathrm{cm}$ is the number of sample points, the land types of which were accurately simulated by the model. $t m$ is the total number of sample points.

Due to limitations of historical literature and data, comparison and analysis of the simulation results could only be performed on a partial region and time segment. In this study, a 1930s Japanese military map of (a) Qingdao, (b) Yangtai, (c) Mouping, (d) Tengzhou, (e) Licheng, and (f) Zaozhuang in Shandong was taken as the precision evaluation base map (Data refered from Groups for map collection, 1997). After image geometrical correction (with error smaller than 
half of a grid cell) and projection transformation, 268 random sample points were chosen to perform visual discrimination. The results are shown in Table 5 and Fig. 3.

Table 5 accuracy of modeling result in typical regions

\begin{tabular}{cccc}
\hline Regions & $p \_a$ & $u \_a$ & $o \_a$ \\
\hline Qingdao City (a) & $28.57 \%$ & $100.00 \%$ & $60.00 \%$ \\
Yantai City (b) & $43.75 \%$ & $87.50 \%$ & $65.63 \%$ \\
Muping County (c) & $68.75 \%$ & $88.00 \%$ & $62.22 \%$ \\
Tengzhou City (d) & $54.05 \%$ & $76.92 \%$ & $55.10 \%$ \\
Lichen County (e) & $60.53 \%$ & $67.65 \%$ & $58.82 \%$ \\
Zaozhuang City (f) & $71.79 \%$ & $87.50 \%$ & $72.22 \%$ \\
Average Value & $59.09 \%$ & $80.62 \%$ & $62.31 \%$ \\
\hline
\end{tabular}



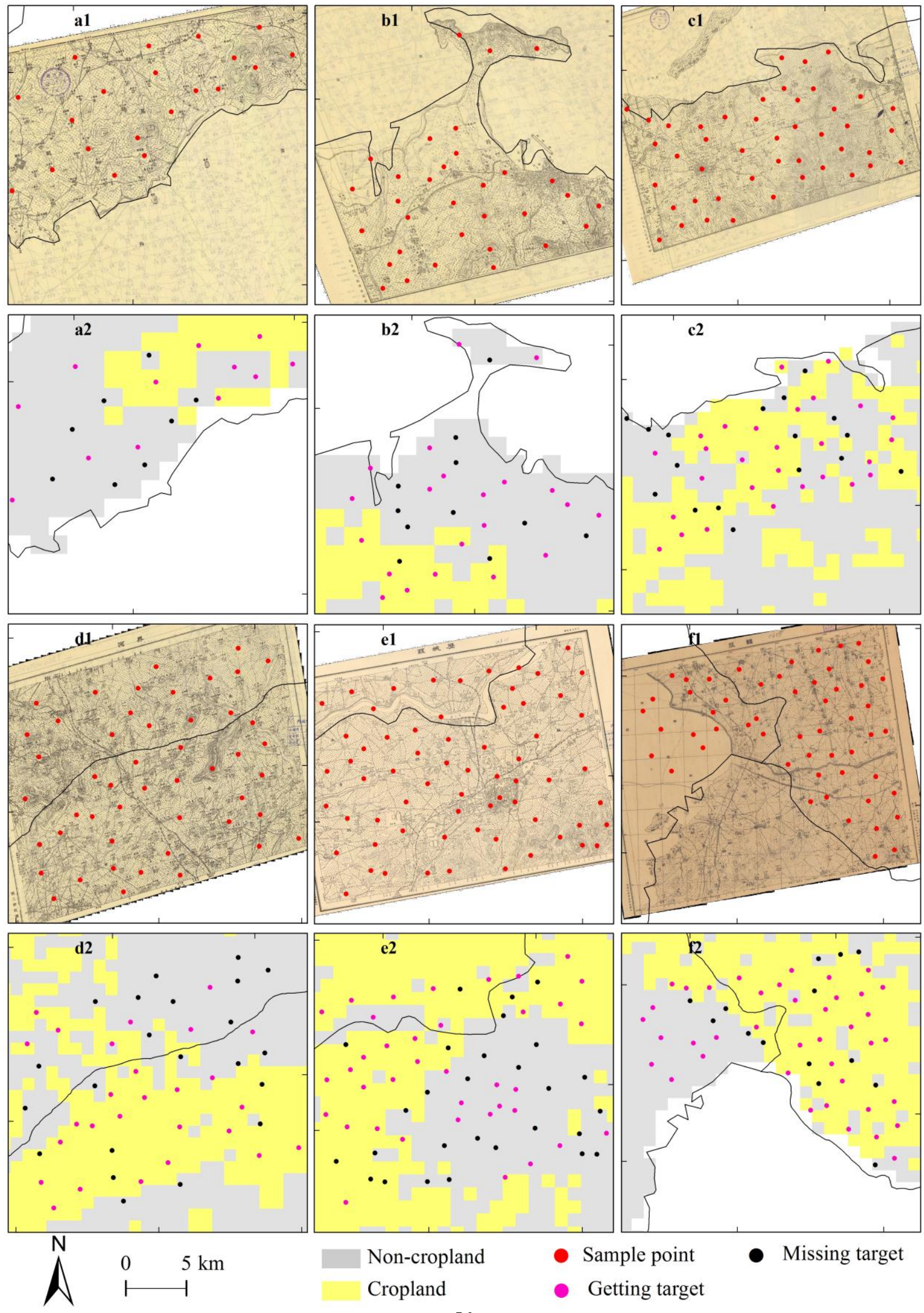

$\bigwedge^{1} \quad \begin{array}{ll}0 & 5 \mathrm{~km}\end{array}$

Non-cropland

Cropland
Sample point

- Getting target
Missing target 
Fig.3 accuracy result between historical maps (1930s) and modeling maps (1933) by way of point to point in

typical regions

Among the randomly selected 268 points, 129 points were simulated as cropland, 104 of which demonstrated the same land type (cropland) as in the historical map. In the sample points set, 176 points were cropland in historical map, while 167 points showed the same land type (cropland and non-cropland) between simulation results and the historical map. It can be derived that the average producer precision, user precision, and overall precision of the six counties and cities were $59.09 \%, 80.62 \%$, and $62.31 \%$, respectively. Except for the overall precision in Tengzhou and Licheng $(<60 \%)$ and the producer precision in Qingdao, Yantai, and Tengzhou $(<55 \%)$, the other precision parameters in the cities were fairly high. Overall, the model constructed in this study showed high simulation precision. The parameter settings were reasonable, and enabled across-region, multi-period cropland reconstruction simulation.

\subsubsection{Results of Model}

Based on the above model and parameter settings, the final simulation results are shown in Fig. 4. It can be seen that historical cropland in the first year of reconstruction was mainly distributed on the north side of the Yellow river (i.e., Dongchang, Jinan, Wuding, and Qingzhou), in the west Shandong plain, and on the west side of the Beijing-Hangzhou canal river (e.g., Tai'an, Caozhou. and Jining). There were dispersed croplands in other regions. These regions had abundant water resources, high soil fertility, and even terrain, and these areas were historically high quality grain production bases in Shandong. Subsequently, the historical cropland spatial pattern in Shandong showed expansion towards the east and the south as well as along the coast line and mountainous area. Specifically, it expanded east along the Laizhou bay towards Qingzhou, Laizhou, and Dengzhou. It also expanded south along the west side of the Beijing-Hangzhou canal towards 
Yanzhou, Caozhou, and Jining. Meanwhile, the cropland density in Jiaodong near Huanghai, the Shandong peninsula, and the mid-south Shandong mountainous area continually increased. The evolution tendency is generally consistent with the cropland variation pattern in Shandong over the 300 year study period. Specifically, cropland quantity dropped abruptly as a result of war during the early Qing dynasty. The cropland was mainly distributed in the Northwest and Southwest Shandong plain along the Yellow River. With the promulgation of a series of encouraging policies such as no tax for isolated cropland as well as water conservancy construction during the Kangxi, Yongzheng, and Qianlong periods (Peng, 1990; Cheng, 2010), the abandoned lands at the end of Ming dynasty were effectively recovered, resulting in a significant increase in cropland quantity. The spatial pattern demonstrated expansion towards the east and south in even terrain and high fertility areas (He, Dai \& Ge, 2005). After the massive reclamation, the arable lands in Shandong were almost completely in use during the Jiadao period. This resulted in severe human-land conflict. Farmers started to cultivate American crops, which have no preference for soil type. Thus, lands with marginally fertile soil were further developed, which resulted in a spatial pattern of expansion towards Yantai, Weihai, and low hilly areas in the middle of Shandong (Yang et al. 2015a).
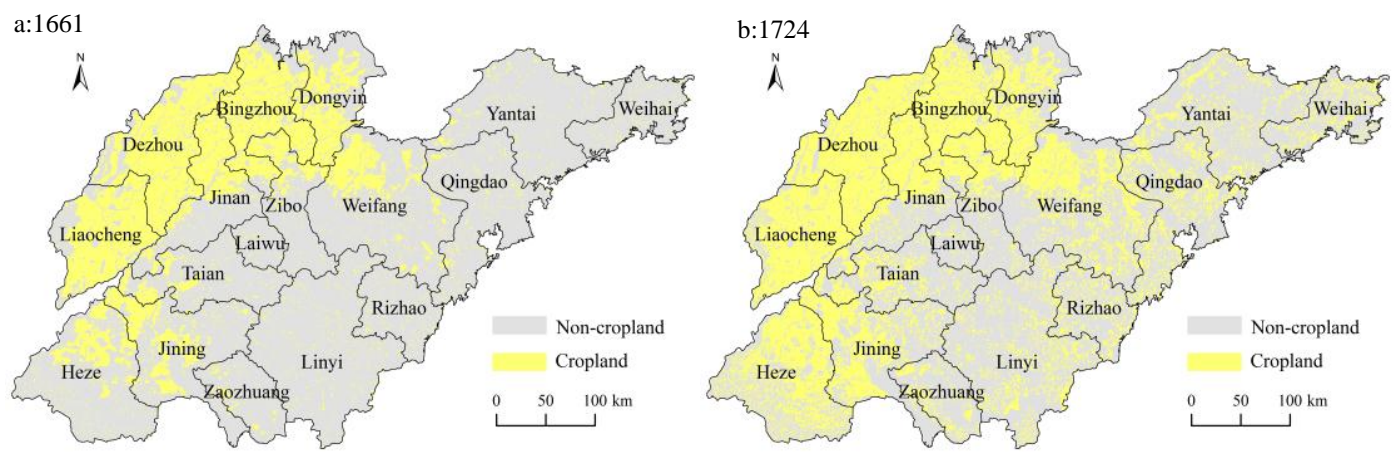

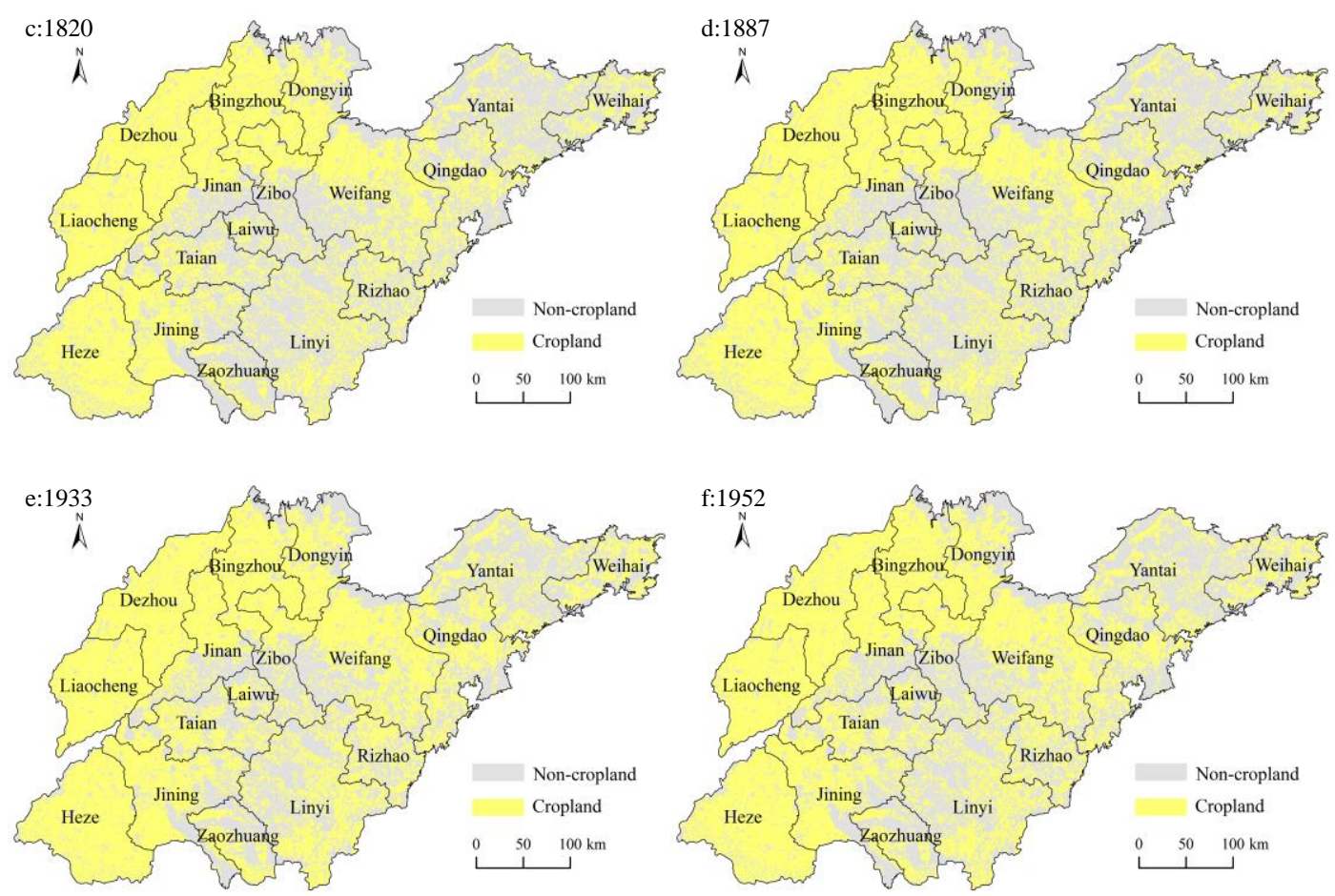

Fig.4 The reconstruction results of cropland in Shandong province in China during 1661 to 1952

\section{Discussion and Conclusions}

\subsection{Discussions}

In order to analyze the difference between the reconstructed results and existing data sets, the results were compared and analyzed at the grid cell scale. Specifically, data for Shandong in a similar time segment as the study period were selected from CHCTR (Chinese Historical Cropland of Traditional Region), CHCD (Chinese Hitorical Cropland Dataset), and HYDE 3.1 data sets (Klein Goldewijk \& Batties, 1997; Yang et al., 2015b; Li, He \& Zhang, 2015) to compare grid cell relative error. In order to facilitate data processing, data were expressed as cultivation rate (percentage). Grid resolution was rescaled up to $10 \mathrm{~km} \times 10 \mathrm{~km}$ (Yang et al., 2015b), and the results are shown in Fig.5. 


Note: a represents CHCTR referred from Yang et al. 2015b; b represents CHCD inferred from Li, He \&

Zhang, 2015; c is HYDE3.1 which was downloaded from http://themasites.pbl.nl/en/themasite. Non-colored grids in the figure are non-cropland in the reconstructed results. Cells are defined as 1 if the grid relative errors exceed 1.

Fig.5 The spatial pattern of relative error between existing datasets and reconstructed results in this paper

From the comparison of different time segments, it can be seen that the relative error between the reconstructed historical cropland spatial pattern and the CHCTR, CHCD, and HYDE 3.1 data sets was stable for the northwest Shandong plain area on the north side of the Yellow River. The relative error was small $( \pm 10 \%)$, except for $>30 \%$ relative error rates for a few individual grid cells. The areas have fertile soil and suitable hydrothermal conditions, therefore the reconstruction results from different methods did not vary significantly in this area. It is worth noting that, in 1661, there was large relative error in the southwest Shandong plain area on the west side of the Beijing-Hangzhou canal. These were mainly positive errors, i.e., the existing data sets showed abundant historical cropland in this area, while the reconstructed results based on the agent model showed less cropland. One possible reason for this trend is that the area is close to Baihua River, Lai River, and Wei River. Even though the southwest Shandong plain had even terrain and abundant water resource, frequent dike breaking on the Yellow River in this area caused flooding in Nanyang Lake and the canal, which ultimately enters Daqing River. During the 18 years between 1644 and 1662, the average annual flood rate was 5, causing disasters to a total of 183 states and counties $(\mathbf{L i}, \mathbf{1 9 9 3})$. From the perspective of cultivation risks, the area was not suitable for agricultural cultivation. The reconstruction method in the existing data set did not take flood disasters into account, whereas our multi-agent model automatically avoided the non-suitable area. In the mid-south Shandong mountainous area, the relative error between data 
sets was small, generally within $\pm 30 \%$. This indicates that the "top-down" distribution method and "bottom-up" spatial evolution method can effectively avoid mountains, hills, and other non-cultivable areas. Only when there is a high population pressure will the area be cultivated. In the Shandong peninsula and hilly areas of Jiaodong, the range of relative error was large. Most of these error values were within $\pm 70 \%$, with some reaching $100 \%$ for some regions. The errors are mostly positive. The causes of the differences lie in various aspects. One is that the cropland quantities of CHCD and HYDE 3.1 data set are, to some extent, different from that of the current study (Cao, Jin \& Zhou, 2013). The other is that neighbor sea area, regulation department, and salt solarization were considered in the model. Multi-agents would prioritize government encouraged cultivation areas in their selection. Thus, it is reasonable that there were some positive error grids in the mountainous areas of the middle Shandong peninsula where there was low suitability.

In order to further analyze the rationality of the model with respect to total cropland quantity reconstruction in each county (region), the results were compared at the county level with the results of Ye et al. (2015). To unify calculation scope and eliminate magnitude order differences, contemporary county level administrative boundaries were used to divide spatial analysis units. Cultivation rate (ratio between cultivation area and administrative area) was used as the evaluation indicator, and it was divided into 6 levels according to Ye et al. (2015)'s classification standard. Meanwhile, the difference level of cultivation rate was characterized by subtracting the reconstruction results from Ye et al. (2015)'s results, and therefore it could be divided into 5 classes, which is XI I, II, III and IV type, respectively. For exemple, XI type represents that this study have same level of cultivation rate with Ye et al. (2015)' s in a county, and I, II, III, IV type is one, two, three, and four grade difference in each other, respectively. The results are shown in 
Fig. 6 and Table 6.
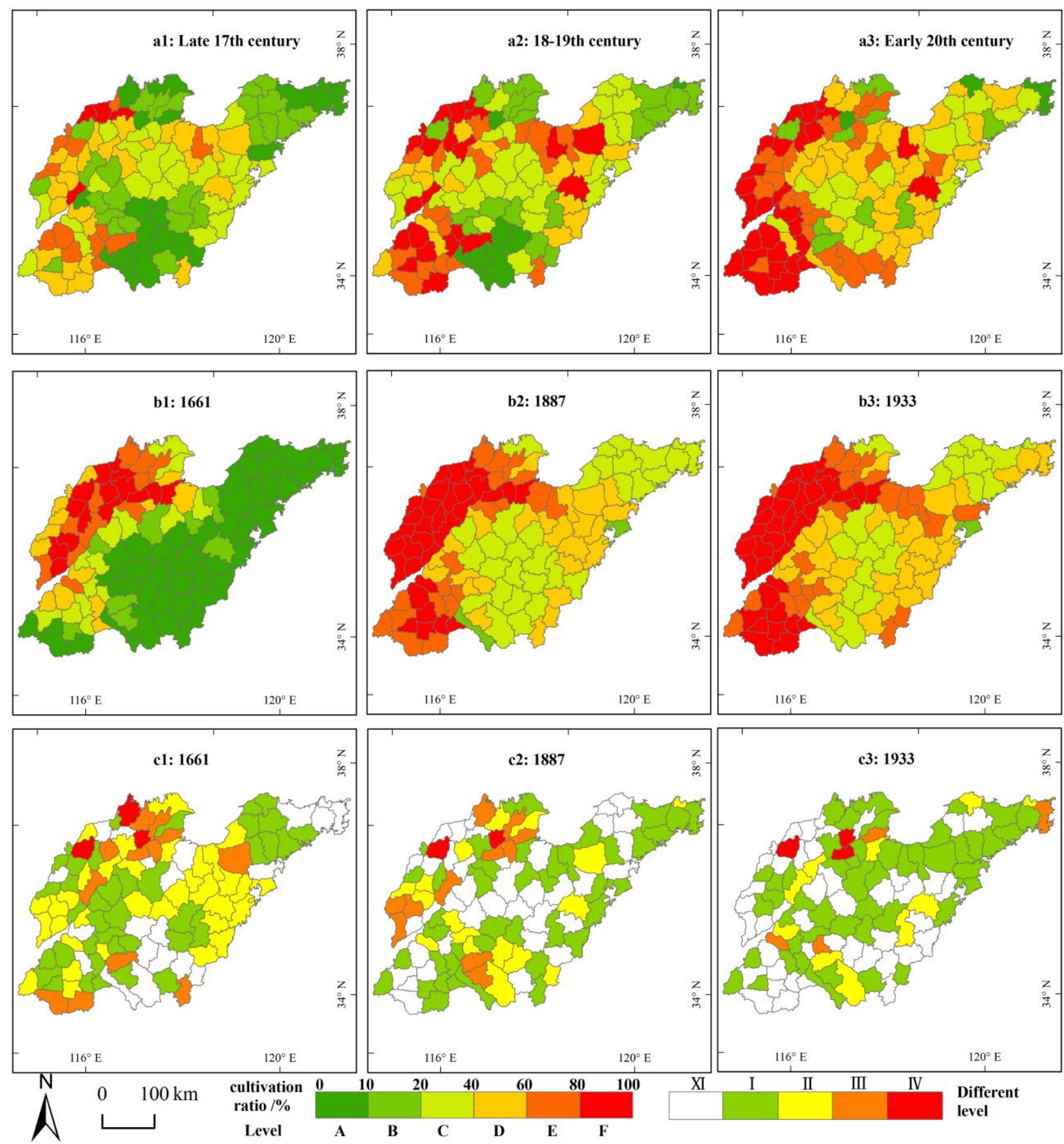

Note: a represents Ye et al. (2015)'s results; b is the result of this study; $c$ is the difference level of cultivation

rate.

Fig.6 Cropland area fraction for each modern county-level 
Table 6 the pattern and diversity of cultivation ratios in different degree for each modern county-level

\begin{tabular}{|c|c|c|c|c|c|c|}
\hline $\begin{array}{l}\text { Level of cultivation ratios } \\
\qquad(\mathrm{a} / \mathrm{b})\end{array}$ & A & B & $\mathrm{C}$ & D & E & $\mathrm{F}$ \\
\hline 1661 & $48 / 19$ & $8 / 25$ & $14 / 24$ & $14 / 25$ & $11 / 13$ & $15 / 4$ \\
\hline 1887 & $0 / 7$ & $2 / 18$ & $32 / 30$ & $24 / 16$ & $20 / 17$ & $32 / 22$ \\
\hline 1933 & $0 / 4$ & $1 / 9$ & $21 / 17$ & $30 / 30$ & $22 / 22$ & $36 / 28$ \\
\hline $\begin{array}{c}\text { Difference level of } \\
\text { cultivation ratios }\end{array}$ & XI & I & II & III & IV & \\
\hline 1661 & 21 & 39 & 35 & 12 & 3 & \\
\hline 1887 & 39 & 41 & 17 & 11 & 2 & \\
\hline 1933 & 45 & 48 & 10 & 4 & 3 & \\
\hline
\end{tabular}

Note: in the equation (a / b), a and b represents the this study' result and Ye et al.2015's results respectively.

It can be observed from Fig. 6 and Table 6 that at each time cross section the two data sets closely matched with respect to cultivation rate distribution, showing an overall consistent change tendency. High cultivation rate areas were concentrated in the Northwest and Southwest Shandong plain and some counties near Jiaozhou Bay, whereas early stage low cultivation rate areas were distributed mainly in the Shandong peninsula and the mid-south Shandong mountainous area. With more intense human-land conflict and expanded cultivation range, the late stage low cultivation rate area became gradually scattered. The number of county units with no difference (XI type) and one grade difference (I type) in cultivation grade between two data sets gradually increased, from 21 and 39 in the early Qing dynasty to 45 and 48 in 1933 . In contrast, the number of county units with II type and III type differences decreased, from 35 and 12 in the early Qing dynasty to 10 and 4 in 1933. Moreover, the number with IV type difference was small (2-3 units), and did not obviously change. In Ye et al. (2015), the extent of reconstruction in cropland areas in Shandong during the 17th century, 18th 19th centuries, the beginning of the 20th century, and the $1980 \mathrm{~s}$ are 4.51 million ha, 6.51 million ha, 7.52 million ha and 8.53 million ha, respectively. At provincial level, the difference between Ye et al. (2015) 
and Cao et al. (2013) in the cropland area are insignificant during the stage of the Shun-Kang-Yong Kingdom (1644-1735), then significant. However, the reconstructed cropland pattern and tendency at county level between this study and Ye et al. (2015) became increasingly similar, and the differences decreased over time. Besides, the archives and historical records are more abundant and accurate in middle-latter period of Qing Dynasty, even the part of modeling parameters are closer the real spatial distribution. So, the results indicate that multi-agent system have a good ability to simulate and reconstruct the spatial distribution of recent cropland at county level.

The above grid cell scale and county level comparison indicated that the reconstructed historical cropland spatial pattern in this study closely matched data recovered from historical literature in terms of overall variation and cultivation tendency. The deviation also decreased over time. Grid cell cultivation rate demonstrated a spatial pattern more consistent with the actual condition. It can be concluded that the multi-agent model proposed in this study possessed a certain degree of rationality and suitability for simulation of historical cropland pattern.

\subsection{Conclusions}

(1) Considering the complex activities and interactions of behavioral subjects during cultivation area selection, a historical cropland spatial pattern reconstruction model was built based on a combination of a multi-agent system and cellular automata. Two types of agent, i.e., government agent and farmer agent, were selected to characterize the decision-making of behavioral subjects. Through use control and encouragement by the government agent as well as cultivation decisions and negotiation mechanism of farmer agents, historical cropland spatial pattern reconstruction was fulfilled.

(2) An empirical study was carried out in Shandong using the reconstruction model. Six 
example areas were chosen to evaluate the model precision using a point-to-point direct comparison method. The results showed that for 1933 the simulation results showed high producer precision, user precision, and overall precision. The results were generally trustworthy. The historical cropland spatial expansion pattern showed expansion towards the east and the south at first. The pattern then exhibited a tendency of expansion along the coast line and mountainous area, which conforms to the actual condition of cropland expansion in Shandong. This suggests that the model possesses a certain degree of suitability for reconstruction of historical cropland spatial patterns.

(3) Contemporary county level and grid scale comparison of the reconstruction results with existing data sets showed that the reconstructed historical cropland spatial pattern in this study closely matched data recovered from historical literature in term of overall variation and cultivation tendency. Furthermore, the deviation gradually decreased. Grid cultivation rate demonstrated a spatial pattern more consistent with the actual condition.

\section{Acknowledgements}

We thank National Science Foundation of China (No. 41340016 and 41201386), National Basic Research Program of China (No. 2011CB952001) and the Graduate Scientific Research Innovation Projects of Education Department of Jiangsu Province, China (Grant No. KYLX15_0040) for the financial support on this research. The authors thank Dr. Xie Zhongkai, Zhang Honghui, Long Ying, and Li Shicheng for helping me to finish this thesis perfectly.

\section{References}

Bai S. Y., Zhang S.W., \&Zhang Y.Z. (2007). Digital rebuilding of LUCC spatial-temporal distribution of the last 100 years: Taking Dorbod Mongolian autonomous county in Daqing cityas an example. Acta Geographic Sinica, 62(4): 427-436. (in Chinese) 
Bai W. Q., \&Zhao S. D. (2001). An analysis on driving force system of land use changes.

Resources Science, 23(3): 39-41. (in Chinese)

Brown L. A, \&Moore E. G. (1970). The intra-urban migration process: A perspective. Geografiska Annaler, 52B: 1-13.

Cao X., Jin X. B., \&Zhou Y.K. (2013). Research on cropland data recovery and reconstruction in the Qing Dynasty: Method and case study. Acta Geographica Sinica, 68(02): 45-256.(in Chinese)

Cheng F. (2010). Commentary review on cultivation of land in Shandong of Qing Dynasty. History Teaching, (8): 32-36. (in Chinese)

Dominik K., Jacek K., Natalia K., Natalia K., Elzbieta Z., krzysztof O., Katarzyna O., Urs G., Catalina M., \&Volker C. R. (2016). Broad scale forest cover reconstruction from historical topographic maps. Applied Geography, 67, 39-48. DOI:10.1016/j.apgeog.2015.12.003

Fang X. Q., Ye Y., Ge Q.S., \&Zhen J. Y.(2005). Land Exploitation in the Northeast China during the Qing Dynasty Inferred from the Development of Town System. Scientia Geographica Sinica, 25(02):129-134. (in Chinese)

Feddema J. J., Oleson K. W., Bonan G. B., Mearns L. O., Buja L. E., Meehl G. A., \&Washington W. M.(2005). The importance of land-cover change in simulating future climates. Science, 310(5754), 1674-1678.

Feng Y.H., Zhang S.H., He F.N., \&Zhou Z. Y.( 2014). Separate reconstruction of Chinese cropland grid data in the 20th century. Progress in Geography, 33(11): 1546-1555. (in Chinese) 
Feng Z.M., Liu B.Q., \&Yang Y.Z., (2005). A study of the changing trend of Chinese cultivated land amount and data reconstructing: 1949-2003. Journal of Natural Resources, 20(1): 35-43. (in Chinese)

Foley J. A., DeFries R., Asner G. P., Barford C., Bonan G., Carpenter S. R., Stuart Chapin F., Kucharik C. J., Monfreda C. M., Patz J. A., Prentice I. C., Ramankutty N., \&Snyder P. K. ( 2005). Global consequence of land use. Science, 309(5734):570-574.

Groups for map collection. (1997).The directory of historical map in Beijing Library of China. Beijing. Beijing Library Press, ISBN:7501312664.(in Chinese)

He F. N., Li S. C., \&Zhang X. Z. ( 2015). A spatially explicit reconstruction of forest cover in Chinaover 1700-2000. Global and Planetary Change, 131: 73-81.

He F. N., Dai J. H., \&Ge Q. S. (2005). An analysis of reclamation trend in the early Qing Dynasty from the view point of Kangxi to Qianlong cultivation and reclamation policies. Geographical Research, 24(6): 878-888. (in Chinese)

He F.N, Li S.C., Zhang X.Z., Ge Q. S., \&Dai J. H. (2012). Comparisons of reconstructed cropland area from multiple datasets for the traditional cultivated region of China in the last 300 years. Acta Geographica Sinica, 67(009): 1190-1200. (in Chinese)

He F.N., Li S. C., \&Zhang X. Z. (2011). The reconstruction of cropland area and its spatial distribution pattern in the mid-northern Song dynasty. Acta Geographica Sinica, 66(11): 1531-1539. (in Chinese)

Hurtt G C, Frolking S, Fearon M G, Moore B., Shevliakova E., Malyshev S., Pacala S.W., \& Houghton R.A.(2006). The underpinnings of land-use history: three centuries of global gridded 
land-use transitions, wood-harvest activity, and resulting secondary lands. Global Change Biology, 12(7): 1208-1229.

Ji L. Z. (2014). Changes of Coastal Salterns in Shandong Province in Qing Dynasty. Salt Industry History Research, 03:81-86. (in Chinese)

Kaplan J.O., Krumhardt K.M., \&Zimmermann N. (2009). The prehistoric and preindustrial deforestation of Europe. Quat Sci Rev 28:3016-3034. doi:10.1016/j.quascirev.2009.09.028.

Klein Goldewijk. K., \&Battjes J. J. (1997). A hundred year (1890-1990) database for integrated environmental assessments (HYDE, version 1.1).National institute of public health and the environment (RIVM), Bilthoven, the Netherlands.Land use and cover change science/research plan IGBP Report No. 35: HDP Report (7), 60-63.

Klein Goldewijk. K (2001). Estimating global land use change over the past 300 years: The HYDE Database. Global Biogeochemical Cycles, 15(2):417-433.

Klein Goldewijk. K., \&Navin R. (2004). Land cover change over the last three centuries due to human activities: The availability of new global data sets. Geojournal, 61(4):335-344.

Li B. B., Fang X.Q., Ye Y., \&Zhang X. Z. (2010). Accuracy assessment of global historical cropland datasets based on regional reconstructed historical data: A case study in Northeast China. Science in China, Series D: Earth Sciences, 40(8): 1048-1059. (in Chinese)

Li L. F. (1993). Agricultural geography of Shandong Province in Ming-Qing dynasty. Xi'an: Shaanxi Normal University. (in Chinese)

Li S. C., He F. N., \&Zhang X. Z. (2015). A spatially explicit reconstruction of cropland cover in China from 1661 to 1996. Regional Environmental Change, 1-12. 
Li S. C., He F. N., \&Zhang X. Z. (2014). An approach of spatially-explicit reconstruction of historical forest in China: A case study in Northeast China. Acta Geographica Sinica, 69(3): 312-322. (in Chinese)

Li .X. B. (1996). A review of the international research on land use/land cover change. Acta Geographic Sinica, 51(6): 553-558. (in Chinese)

Lin S. S., Zheng J. Y., \&He F. N. (2009). Gridding cropland data reconstruction over the agricultural region of China in 1820. J Geogr Sci. 01(19): 36-48.

Lin Y. N., Jin X. B., Yang X. H, Long Y., Guo B. B., Han J., \&Zhou Y. K.(2015). Data set establishment and spatial reconstruction of built-up area in the Mid Qing Dynasty: Method and case study. Geographical Research, 34(12): 2329-2342. (in Chinese)

Liu J. Y., Kuang W. H., Zhang Z. X., Xu X. L., Qin Y. W., Ning J., Zhou W. C., Zhang S. W., Li R. D., Yan C. Z., Wu S. X., Shi X. Z., Jiang N., Yu D. S., Pan X. Z., \&Chi W. F.(2014). Spatiotemporal characteristics, patterns and causes of land usechanges in China since the late 1980s. Acta Geographic Sinica, 69(1): 3-14. (in Chinese)

Liu M. L., \&Tian H. Q. (2010). China's land cover and land use change from 1700 to 2005, estimations from high-resolution satellite data and historical archives. Global Biogeochemical Cycles, 24(3): 1-18. DOI:org/10.1029/2009gb003687.

Liu X. P., Li X., Chen Y. M., Liu T., \&Li S. Y. (2010). Agent-based Model of Residential Location. Acta Geographica Sinica, 65(6): 695-707. (in Chinese) 
Long Y., Jin X. B., Yang X. H., \&Zhou Y. K. (2014). Reconstruction of historical arable land use patterns using constrained cellular automata: A case study of Jiangsu, China. Applied Geography, 52: 67-77.

Long Y., Jin X. B., Li M. Y., Yang X. H., Cao X., \&Zhou Y. K.(2014). A constrained cellular automata model for reconstructing historical arable land in Jiangsu province, Geographical Research, 33(12): 2239-2250. (in Chinese)

Luo J., Zhang J.L., Liu F. G., Chen Q., Zhou Q., \&Zhang H. F. (2014). Reconstruction of cropland spatial patterns for 1726 on Yellow River-Huangshui River Valley in northeast Qinghai-Tibet Plateau. Geographical Research, 33(7): 1285-1296. (in Chinese)

Mazier F., Brostrom A., Bragee P., Fredh D., Stenberg L., Their e G., Sugita S., \& Hammarlund D.(2015).Two hundred years of land-use change in the South Swedish Uplands: comparison of historical map-based estimates with a pollen-based reconstruction using the landscape reconstruction algorithm. Vegetation History and Archaeobotany, 24(05):555-570.

McFadden D. Conditional logic analysis of qualitative choice behavior//Zarembka P//Frontiers in Econometrics. New York: Academic Press, 1974: 105-142.

Pei G. Q. (2014). The transporting pattern and spatiotemporal development of coaling in Shandong Province in Qing Dynasty. Journal of China University of Mining \& Technology, 01:118-124. (in Chinese)

Peng Y. X, (1990). Cultivation history in Qing Dynasty. Beijing. China Agriculture Press, 1-285. (in Chinese) 
Pongratz J., Reick C., Raddatz T., \&Claussen M. (2008). A reconstruction of global agricultural areas and land cover for the last millennium. Global Biogeochemical Cycles, 22(3):1-16.

Ramankutty N., \&Foley J. A. Estimating historical changes in global land cover: Croplands from 1700 to 1992. Biogeochemical Cycles, 1999, 13(4): 997-1027.

Fuchs R., Verburg P. H., Clevers J.G.P.W., \&Herold M. (2015). The potential of old maps and encyclopedias for reconstructing historic European land cover/use change. Applied Geography, 59: 43-55. DOI:10.1016/j.apgeog.2015.02.013.

Shi Z. G., Yan X. D., Yin C. H., \&Wang Z. M. (2007). Effects of historical land cover changes on climate. China Science Bulletin, 52(12):1436-1444. (in Chinese)

Sterling S. M., Ducharne A., \&Polcher J. (2013). The impact of global land-cover change on the terrestrial water cycle. Nature Climate Change, 3(4): 385-390. doi:10.1038/nclimate1690.

Tian H. Q., Banger K., Bo T., \&Badhwal W. K. (2014). History of land use in india during 1880-2010: Large-scale land transformations reconstructed from satellite data and historical archivers. Global and Planetary Change, 121:78-88.

Voldoire A., Eickhout B., Schaeffer M.,Royer J. F., \&Chauvin F. (2007). Climate simulation of the twenty-first century with interactive land-use changes. Climate Dynamics, 29(2-3): 2-3. Wei X. Q., YeY., Zhang Q., \&Fang X. Q. (2015). Methods for cropland reconstruction based on gazetteers in the Qing Dynasty (1644-1911): A case study in Zhili province, China. Applied Geography, 65: 82-92. DOI:10.1016/j.apgeog.2015.11.002 
Xie Y. W., Wang X. Q., Wang G.S.,\&Yu L.(2013). Cultivated land distribution simulation based on grid inmiddle reaches of Heihe river basin in the historical periods. Advances in Earth Science, 28(1): 71-78. (in Chinese)

Yang X. H., Guo B. B., Jin X. B.,Long Y., \&Zhou Y. K. (2015a). Reconstructing spatial distribution of historical cropland in China's traditional cultivated region: Methods and case study. Chinese Geographical Science, 1-15. DOI:10.1007/s11769-015-0753-2

Yang X. H., Jin X. B., Guo B. B., Long Y., \&Zhou Y. K. (2015b). Research on reconstructing spatial distribution of historical cropland over 300years in traditional cultivated regions of China. Global and Planetary Change, 128: 90-102.

Ye D. Z., \&Fu C. B. (2004). Some advance in global change science study. Bulletin of Chinese Academy of Sciences, 19(5): 336-341. (in Chinese)

Ye Y., Wei X. Q., Li F., \&Fang X. Q. (2015). Reconstruction of cropland cover changes in the Shandong Province over the past 300 years. Scientific reports, 5, 13642; doi: 10.1038/srep13642 (2015).

Zhang G. P., Liu J. Y., \&Zhang Z. X. (2003). Spatial-temporal changes of cropland in china for the past 10 years based on remote sensing. Acta Geographica Sinica, 58(3): 323-332. (in Chinese)

Zhang H. H., Jin X. B., Wang L. P., Zhou Y. K., \&Shu B. R. (2015). Multi-agent based modeling of spatiotemporal dynamical urban growth in developing countries: simulating future scenarios of Lianyungang city, China. Stochastic Environmental Research and Risk Assessment, 29:63-78. 
Zhang H. H., Zeng Y. N., Jin X. B., Yin C. L., \&Zou B. (2008). Urban land expansion model based on multi-agent system and application. Acta Geographica Sinica, 63(8): 869-881. (in Chinese)

Zhang L. J., Jiang L. Q., Zhang X. Z., Zhang A. K., \&Jiang C. Y. (2014). Reconstruction of cropland over Heilongjiang Province in the late 19th century. Acta Geographica Sinica, 69(4): 448-458. (in Chinese)

Zhou R. (2001). A general inspection and re-appraisal on area under cultivation in the early period of Qing Dynasty. Jianghan tribune, (09):57-61. (in Chinese)

Zhu F., Cui X.F., \&Miu L. J. (2012).China's spatially-explicit historical land-use data and its reconstruction methodology. Progress in Geography, 31(12), 563-1573. (in Chinese) 